\title{
Stress due to the interseismic back slip and its relation with the focal mechanisms of earthquakes occurring in the Kuril and northeastern Japan arcs
}

\author{
M. Takeuchi*, T. Sato, and T. Shinbo \\ Department of Earth and Environmental Sciences, Hirosaki University, Bunkyo-cho 3, Hirosaki, Aomori 036-8561, Japan \\ (Received October 9, 2007; Revised December 25, 2007; Accepted January 21, 2008; Online published July 4, 2008)
}

\begin{abstract}
Assuming a uniform and inhomogeneous distribution of back slip, based on a realistic configuration of the plate boundary that was newly determined from the distribution of earthquakes, we have investigated if the stress due to the interseismic back slip can explain the focal mechanisms of earthquakes occurring in the Kuril and northeastern Japan arcs. The inhomogeneous back-slip model was taken from the distribution of slip deficit estimated from GPS data collected in recent years. We examined the change in the Coulomb Failure Function ( $\triangle \mathrm{CFF}$ ) for several target faults to evaluate the fitness of the models to the observed focal mechanisms. The results of $\Delta \mathrm{CFF}$ are clearly different in the two back-slip models near the down-dip end of the locked zone. Despite this difference, the models can generally explain the earthquake focal mechanisms in the overriding plate as well as those on the megathrust plate boundary. However, they cannot explain the focal mechanisms of intermediate-depth earthquakes in the double-planed deep seismic zone. Neither can they fully explain the focal mechanisms with the pressure axis parallel to the trench that are observed at the junction of the Kuril and northeastern Japan arcs. Other tectonic processes, such as the transcurrent movement of the forearc sliver along the Kuril arc, may be involved in producing the stress anomaly.
\end{abstract}

Key words: Interseismic loading, subduction zone, back slip, Kuril arc, northeastern Japan arc, oblique subduction, focal mechanism.

\section{Introduction}

The Hokkaido and Tohoku areas of the Japanese islands are located along the convergent margin between the Pacific plate and North American plate (Fig. 1). The focal mechanisms of earthquakes in this region have been investigated extensively using local as well as teleseismic data (e.g., Sasatani, 1976; Hasegawa et al., 1978; Yoshii, 1979; Sato et al., 1980; Umino and Hasegawa, 1982; Suzuki et al., 1983a, b; Umino et al., 1984; Miyamura and Sasatani, 1986; Kosuga et al., 1996; Igarashi et al., 2001). The main results of these investigtions can be summarized as follows. Shallow earthquakes within the overriding lithosphere have $P$-axes almost parallel to the direction of plate convergence. The slip vectors of earthquakes on the megathrust plate boundary are consistent with the relative plate motion. Intermediate and deep-focus earthquakes occurring within the subducted Pacific plate have two distinct types of mechanisms, depending on their locations in the doubled-planed deep seismic zone: those on the upper seismic plane show the mechanism of down-dip compression (DC) while those on the lower seismic plane show the mechanism of downdip extension (DE). Several models, such as the unbending

${ }^{*}$ Now at Witz Corporation, Sakae 15-6, Naka-ku, Nagoya, Aichi 4600008.

Copyright (c) The Society of Geomagnetism and Earth, Planetary and Space Sciences (SGEPSS); The Seismological Society of Japan; The Volcanological Society of Japan; The Geodetic Society of Japan; The Japanese Society for Planetary Sciences; TERRAPUB. model (Engdahl and Scholtz, 1977), sagging model (Sleep, 1979), and thermal expansion model (Goto et al., 1985), have been proposed to interpret the pair of focal mechanisms in the double-planed seismic zone.

Apart from these general trends, the state of stress at the junction of the Kuril and northeastern Japan arcs has been inferred to be anomalous (Shimazaki et al., 1978). This inference was drawn on the basis of triangulation data showing the direction of maximum contraction subparallel to the trench (Nakane, 1973) and by an $M 6.3$ earthquake (January 20,1970) beneath the Hidata belt that had a $P$-axis sub-parallel to the trench (Stauder and Mualchin, 1976) (Fig. 1). It was later strengthened by the occurrence of the 1982 Urakawa-oki earthquake (M 7.1) which also showed a $P$-axis sub-parallel to the trench (Moriya $e t$ al., 1983; Suetsugu and Nakanishi, 1988). The composite focal mechanism solutions for small earthquakes occurring in the vicinity of the Hidaka belt revealed the same trend (Suzuki et al., 1983a). Several researchers attempted to explain this anomaly as being the effect of change in the strike of the plate margin at the Hokkaido corner (Shimazaki et al., 1978; Kato et al., 1980; Minamino and Fujii, 1981; Hashimoto, 1984). However, it has become evident that these models were too simplistic to explain the stress anomaly in terms of the geometry of the plate boundary.

During the past decade, the network of GPS stations over the Japanese islands (GEONET) has provided data that enable crustal deformation during the interseismic period of large earthquakes on the megathrust plate boundary to 


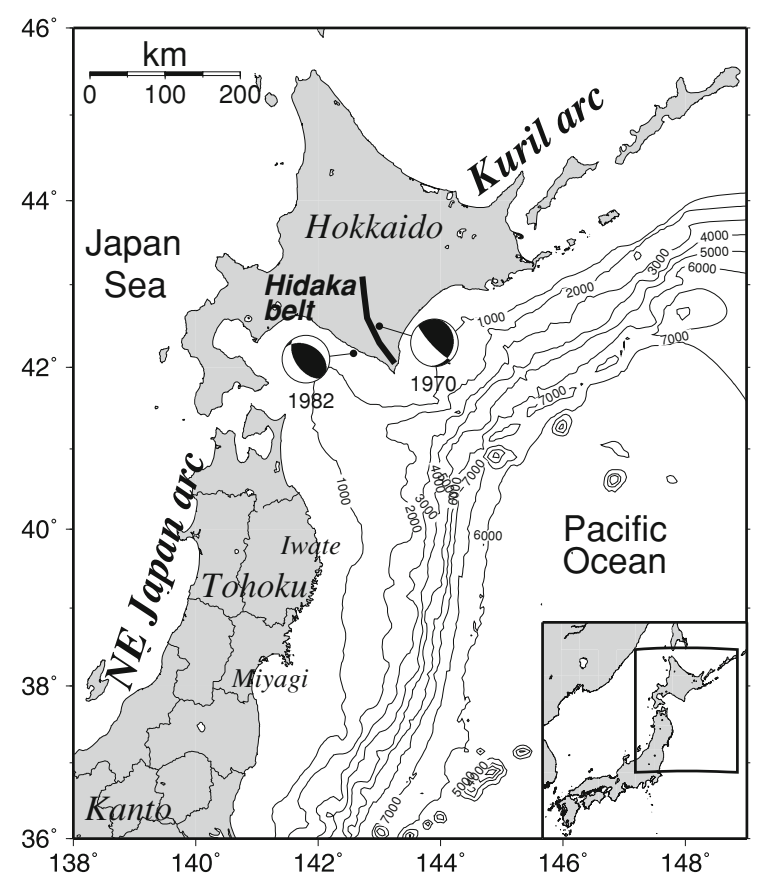

Fig. 1. Map showing the study area. The mechanism diagrams of the 1970 Hidaka and 1981 Urakawa-oki earthquakes are shown. The contours of water depths in the Pacific Ocean are indicated every $1000 \mathrm{~m}$.

be investigated (e.g., Miyazaki et al., 1998; Sagiya et al., 2000). Relying on the so-called back-slip model proposed by Savage (1983), several researchers (e.g., Ito et al., 2000; Nishimura et al., 2000; Mazzotti et al., 2000; Suwa et al., 2006) inverted the GPS data for the slip deficit on the plate boundary along the Kuril and northeastern Japan arcs. The same back-slip model had before been used to estimate the plate coupling coefficient from triangulation data collected during the last century (Shen-Tu and Holt, 1996). Although those investigations revealed the usefulness of the back-slip model for representing surface deformation during the interseismic period, few researchers have asked if the same model is applicable to explaining the focal mechanisms of earthquakes at depths. Douglass and Buffett (1995) questioned the validity of the back-slip model on the grounds that the associated stress field near the down-dip end of the locked zone is inconsistent with the underlying physical assumptions of the model. Savage (1996) argued that the inconsistency would disappear if one includes the stress field associated with the steady state subduction of the oceanic plate, the contribution of which was previously assumed to be negligible for the surface deformation in the overriding plate (Savage, 1983). However, if one considers the differences in mechanical properties that distinguish the locked zone from the portion of the plate boundary where stable sliding occurs, it is not entirely certain that the superposition of the two separate solutions is allowed (Douglass and Buffert, 1996). Zhao and Takemoto (2000) attempted to overcome the defect of the back-slip model by modifying the kinematic constraints on the plate boundary.

Given these circumstances, we suggest that it is important to investigate the stress field due to the back slip using a realistic configuration of plate boundary and to clarify if the back-slip model can explain the focal mechanisms of earthquakes at depths. In this paper, we first determine the configuration of the upper plate boundary using the distribution of earthquakes. We then calculate the stress fields due to the back slip assuming two different distributions of back slip on the plate interface. One is a uniform distribution of back slip and the other is an inhomogeneous distribution that is similar to the slip deficit estimated from the GPS data in recent years. We demonstrate the change in the Coulomb Failure Function $(\triangle \mathrm{CFF}$ ) for several target faults that are representative of the earthquake focal mechanisms in this region. From these results, we evaluate the fitness of the back-slip models to the observed focal mechanisms and discuss the usefulness and limitations of the back-slip model in representing the stress field at depths.

\section{Back Slip on a Realistic Configuration of Upper Plate Interface}

We determined the configuration of the upper plate interface using the distribution of earthquakes in the study area. To this end, we used the hypocenter parameters listed in the Annual Seismological Bulletin of Japan (CD ROM) published by the Japan Meteorological Agency (JMA). The accuracies of the JMA hypocenter parameters have improved since 1997 when the JMA first started to locate hypocenters using a number of stations of Japanese national universities and the National Research Institute for Earth Science and Disaster Prevention (NIED). For our investigation, we used the data on earthquakes for the period of 1997-2003.

Based on the results of earlier studies (Hasegawa et al., 1983; Zhao et al., 1997; Katsumata et al., 2003; Koketsu et al., 2004), we set up an initial model and cut a total of 38 cross sections that orient nearly perpendicular to the depth contours of the initial model (Fig. 2). Figure 3 shows an example of the relationship between the distribution of earthquakes and the location of the upper plate interface determined from it. We sampled earthquakes within a distance of $40 \mathrm{~km}$ from each vertical cross section. Since offshore hypocenter parameters suffer from large errors, we consulted the crustal structures obtained from the ocean bottom seismographic data (IFREE/JAMSTEC, 2007) when we constrained the depth of the plate interface in the shallower part. The location of the plate interface below a depth of about $40 \mathrm{~km}$ was determined using data on earthquake distribution only, based on the assumption that the upper plate interface is located near the upper end of the dipping seismic zone. One-dimensional data thus obtained for all the profiles were integrated to create a two-dimensional grid data. These steps were carried out using a computer-aided graphic tool called 'CHIKAKU DB' (Kanai et al., 2005). The configuration of the upper plate interface determined in our study is shown in Figs. 2 and 4. In the Kuril arc, our model, at depths shallower than about $150 \mathrm{~km}$, is in almost perfect agreement with previous models reported by Katsumata et al. (2003) and Koketsu et al. (2004). The models of these two groups of researchers do not provide the location of the upper plate boundary at depths greater than $150 \mathrm{~km}$. At depths greater than $150 \mathrm{~km}$ the junction is shallower in our model than in that of Hasegawa et al. (1983). South of the junction, at depths greater than $60 \mathrm{~km}$, the present model is deeper than previous models 


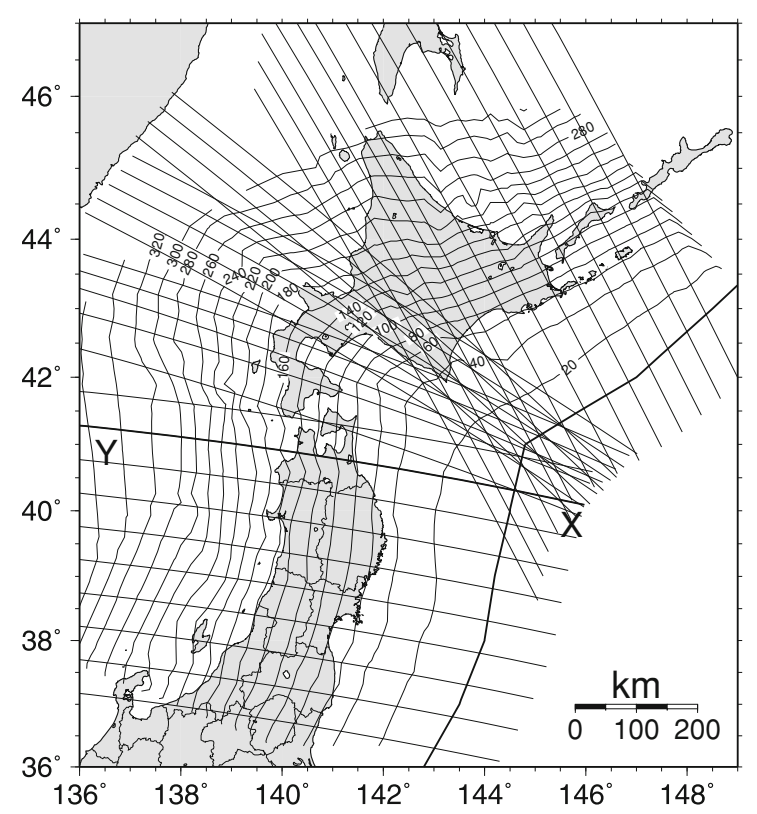

Fig. 2. Locations of vertical cross sections used for determining one-dimensional model of the upper plate boundary. Contours every $20 \mathrm{~km}$ indicate the depth to the upper plate boundary determined in this study. The line $\mathrm{X}-\mathrm{Y}$ denotes the location of profile for which the distribution of earthquakes is shown in Fig. 3.

by Hasegawa et al. (1983) and Matsuzawa et al. (1990). At depths greater than about $150 \mathrm{~km}$ our model may be affected by the non-uniform seismicity of the double-planed seismic zone (Igarashi et al., 2001). Where the seismicity of the upper seismic zone is lower than that of the lower seismic zone, the depth of the plate boundary may appear to be deeper than it actually is. In the present study, however, the accuracy of the plate configuration in the deeper part is less important because the back slip is estimated to be distributed mainly over the shallower part of the plate boundary.

We approximated the curvilinear plate interface using an aggregate of rectangular faults. The attitude of each rectangular fault was fitted to the local strike and dip of the plate interface. In an area away from the junction of the Kuril and northeastern Japan arcs, the sizes of the faults are taken to be about $30 \mathrm{~km}$ along the dip direction and 20-30 km along the strike direction. In the vicinity of the junction where the curvature of the plate interface is large, the fault widths were set to be about twofold smaller than that in the surrounding areas.

It is not certain which distribution of back slip should be assumed when we intend to compare the stress due to the back slip with the focal mechanisms of earthquakes occurring during the last few decades. We therefore tentatively assumed two extreme cases: one is a uniform distribution of back slip on a locked zone of plate boundary, and the other is a distribution which takes after the distribution of slip deficit estimated from recent GPS data (1997-2001) by Suwa et al. (2006). The locked part of the plate boundary in the uniform back-slip model is shown in Fig. 4. The back slip is constant through the entire locked zone. We assumed the down-dip end of the locked zone to be located at a depth of about $50 \mathrm{~km}$ based on the results obtained by Ito

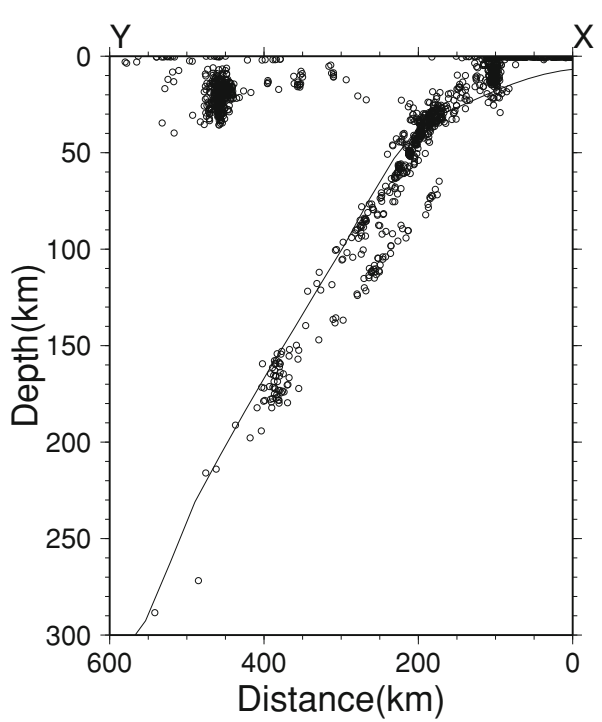

Fig. 3. Cross-sectional view of the distribution of earthquakes for the profile $\mathrm{X}-\mathrm{Y}$ shown in Fig. 2. The curved line indicates the upper plate interface determined from the earthquake distribution. Distance is measured from the trench axis.

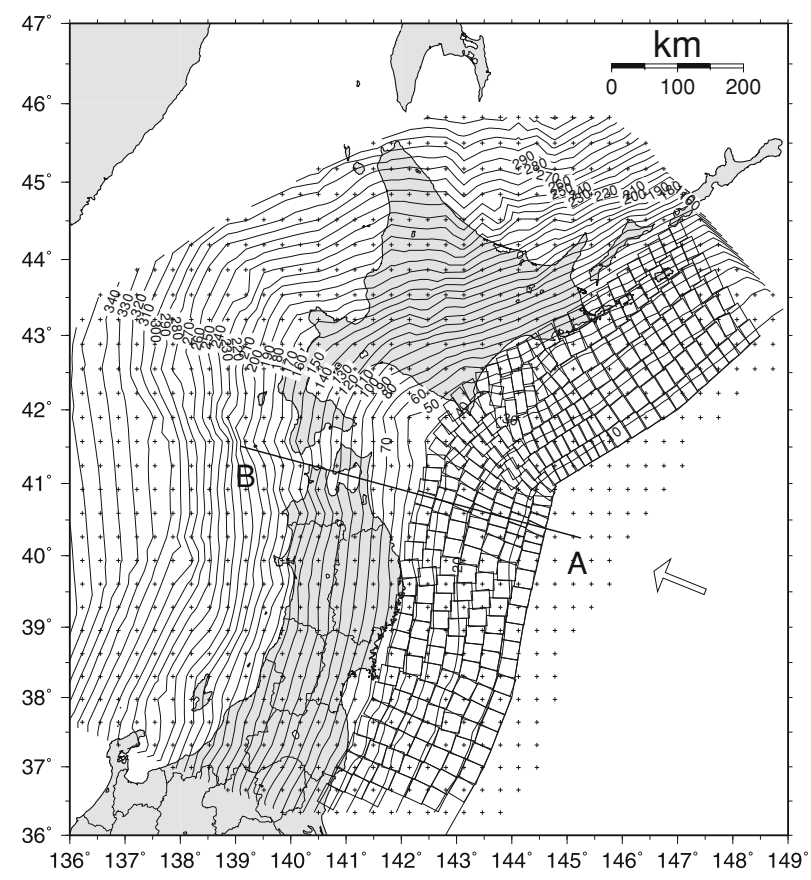

Fig. 4. Distribution of the locked zone in the uniform back-slip model. The locked zone is indicated by an aggregate of rectangular faults on the upper plate boundary. The arrow shows the direction of plate convergence. The line $\mathrm{A}-\mathrm{B}$ indicates the profile for which $\triangle \mathrm{CFF}$ for $\mathrm{DC}$ and DE-type target faults are shown in Figs. 10 and 11. Contours every $10 \mathrm{~km}$ indicate the depths to the upper plate boundary determined in this study. Crosses indicate the grid points where the depths of upper plate boundary are obtained using the CHIKAKU DB (Kanai et al., 2005).

et al. (2000) and Mozzotti et al. (2000). Although the upper end of the locked zone may be some distance away from the trench axis toward the landward side (Hirata et al., 1985), it was assumed to extend up to the trench axis, which is about at a depth of about $6 \mathrm{~km}$ in the present model. Figure 5 shows the distribution of back slip in the inhomogeneous model. The back slip is large off Hokkaido and Miyagi, and 


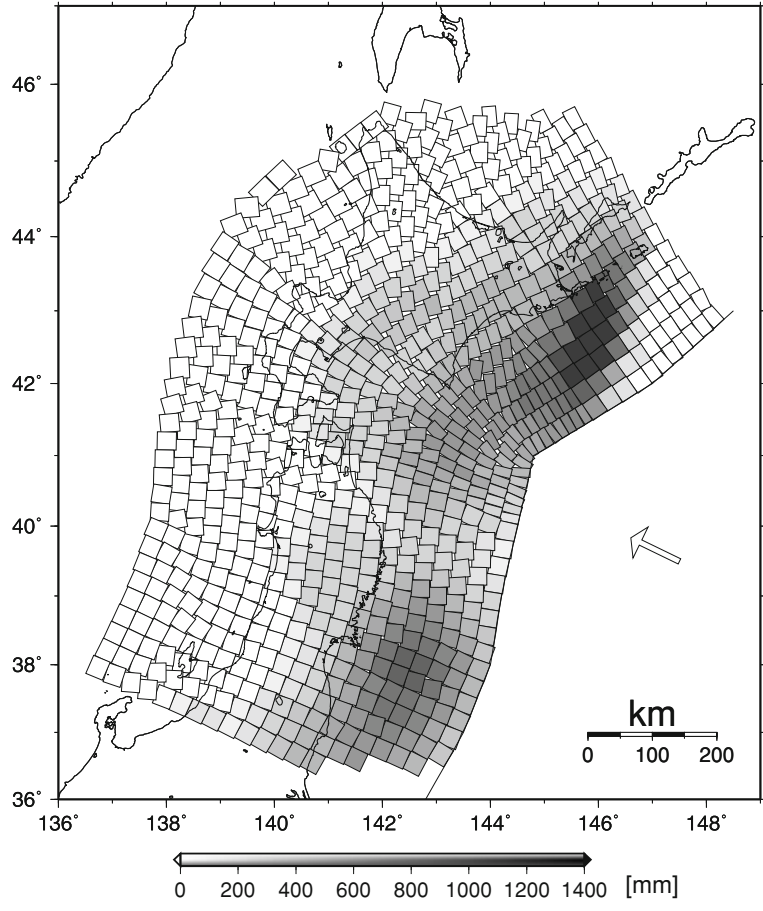

Fig. 5. Distribution of back slip in the inhomogeneous back-slip model. The amount of back slip shown here is about tenfold higher than the yearly slip deficit estimated from the GPS data from 1997 to 2001 by Suwa et al. (2006). The arrow shows the direction of plate convergence.

small off Iwate. In contrast to the uniform model, the back slip varies along the trench and is distributed up to much deeper part, especially under Hokkaido. While the change in the back slip across the down-dip end of the locked zone is discontinuous in the uniform model, the back slip in the inhomogeneous model drops off slowly with increasing depth. In the back-slip model of Savage (1983), the locking of the relative plate motion is represented by a normal fault on the plate interface. The rake of the normal fault was determined from the global plate model, NUVEL-1A (DeMets et al., 1994), in which the Pacific plate moves toward $\mathrm{N} 64^{\circ} \mathrm{W}$ relative to the North American plate at a rate of about $8 \mathrm{~cm} / \mathrm{yr}$ in this part of the plate boundary.

\section{3. $\Delta \mathrm{CFF}$ for Representative Target Faults}

We assumed a uniform elastic half-space and used the formulae derived by Okada (1992) to calculate the stress field due to the back slip. We assumed a Poisson ratio of 0.25 and a rigidity of $50 \mathrm{GPa}$. The rigidity corresponds to the value at the bottom of the crust (Anderson, 1989). The discrepancy between the deformations calculated for a halfspace flat model and a realistic spherically layered model is discussed in the literature (Okubo, 1993; Sun and Okubo, 1993). Although the deformation calculated for the present half-space model may require a revision in details when compared with a realistic spherical model, the results to be described in the following sections would-on the wholeremain unchanged.

In the following, we show the change in the $\triangle \mathrm{CFF}$ for several target faults since $\triangle \mathrm{CFF}$ allows us to easily evaluate the fitness of the stress field to a particular focal mechanism. Given the fault parameters of target event, $\triangle \mathrm{CFF}$ is calculated as

$$
\Delta \mathrm{CFF}=\Delta \tau-\mu \Delta \sigma_{n}
$$

where $\Delta \tau$ is the change in the slip component of shear stress on the target fault, $\Delta \sigma_{n}$ is the change in normal stress, and $\mu$ is the coefficient of internal friction, which was assumed to be 0.4 . For the uniform back-slip model, we used a constant back slip of $1 \mathrm{~m}$, which corresponds to the slip deficit that can be accumulated in about 10 years if the plate coupling is complete. For the inhomogeneous model, we used a tenfold higher value for the back slip per year to match the amount of back slip given for the uniform model. The total seismic moments are $1.1 \times 10^{22}$ and $8.9 \times 10^{21} \mathrm{~N}$ m for the uniform and inhomogeneous models, respectively. These roughly correspond to an earthquake of $M_{\mathrm{w}} 8.6$.

Taking into consideration the main feature of focal mechanisms described earlier, we first selected four target faults. The first is the reverse fault located at a depth of $5 \mathrm{~km}$ (Fig. 6). The strike of each reverse fault was assumed to be the same as the local strike of plate interface just beneath the epicenter of the target fault. The dip was taken to be 30 degrees westward. The rake was assumed to be parallel to the direction of relative plate motion. The second target fault is the thrust fault on the dipping plate interface (Fig. 7). The target fault was placed $2 \mathrm{~km}$ below the plate interface to reduce the effect of stress singularities caused by the gaps and overlaps between the neighboring edges of rectangular faults that approximate the curvilinear plate interface. The dip and strike of each thrust fault were assumed to be the same as the local dip and strike of plate interface, respectively. The slip direction is just opposite to the direction of the back slip. The third target fault simulates the DC-type events on the upper seismic plane of the double-planed deep seismic zone (Fig. 8). The target fault was placed $2 \mathrm{~km}$ below the plate interface. The fault strike was assumed to be the same as the local strike of the plate interface beneath the epicenter of each target fault. The dip was assumed to be 45 degrees higher than the local dip of the plate interface, which means that we assumed the sub-vertical plane to be the fault. The slip direction of the hanging wall block was assumed to thrust up in a direction parallel to the relative plate motion. The fourth target fault simulates the DE-type events on the lower seismic plane of the double-planed deep seismic zone (Fig. 9). The target fault was placed $30 \mathrm{~km}$ below the plate interface. The fault strike and dip were assumed to be the same as for the DCtype target fault. However, the slip direction of the hanging wall block was assumed to be just opposite to that for the DC-type target fault.

For the reverse fault within the overriding lithosphere (Fig. 6), $\triangle \mathrm{CFF}$ is generally positive, except for the zone just above the up-dip end of locked zone where it is negative. The variation in its amplitude along the trend of the arc is more obvious in the inhomogeneous back-slip model. The amplitude of $\triangle \mathrm{CFF}$ is proportional to the amount of back slip that varies along the trench. In the uniform backslip model, the positive amplitude decreases south of the junction of the plate margin once above the down-dip end of the locked zone as it goes from the trench to the backarc side. A similar variation in the horizontal compressional 


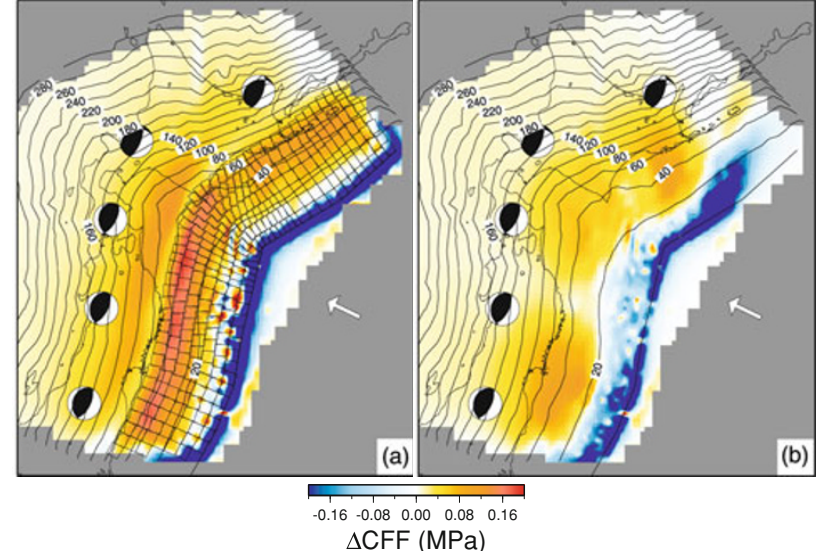

Fig. 6. Plan views of $\triangle \mathrm{CFF}$ for reverse fault at a depth of $5 \mathrm{~km}$. (a) Uniform model and (b) inhomogeneous model. The mechanism diagrams of the target faults at several selected locations are shown. See the text for details of the target fault parameters. The arrow shows the direction of plate convergence. An aggregate of rectangular faults indicate the locked zone in the uniform model.

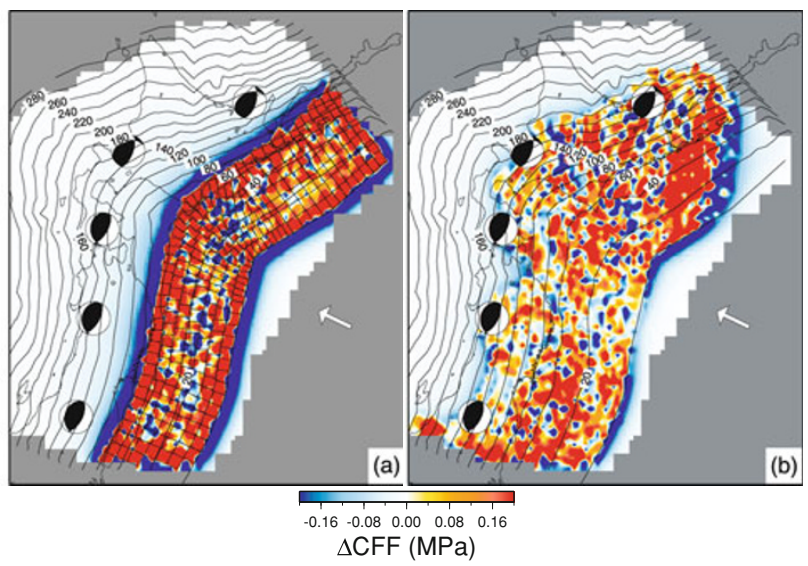

Fig. 7. Plan views of $\triangle \mathrm{CFF}$ for thrust fault at $2 \mathrm{~km}$ below the upper plate interface. (a) Uniform model and (b) inhomogeneous model. The mechanism diagrams of the target faults at several selected locations are shown. See the text for details of the target fault parameters. The arrow shows the direction of plate convergence. An aggregate of rectangular faults indicate the locked zone in the uniform model.

stress was noted by Savage (1983) for the two-dimensional back-slip model. This feature is caused by the strong discontinuous change in the back slip at the down-dip end of the locked zone, which is subdued in the inhomogeneous model in which the back slip drops off slowly at its end. As we will see in the following cases for the other target faults, the differences in $\triangle \mathrm{CFF}$ at the down-dip end of the locked zone between the uniform and the inhomogeneous model are all ascribed to the difference in the distribution pattern of back slip near the down-dip end of the locked zone.

For the thrust fault on the megathrust plate boundary (Fig. 7), $\triangle \mathrm{CFF}$ is strongly positive in the locked zone. The scattered negative blobs are due to the imperfect tiling of rectangular faults. The negative zone at the up-dip end of the locked zone is equally strong for the two models, whereas the negative zone at the down-dip end of the locked zone is much stronger in the uniform model than in the inhomogeneous model. The negative zone at the down-dip

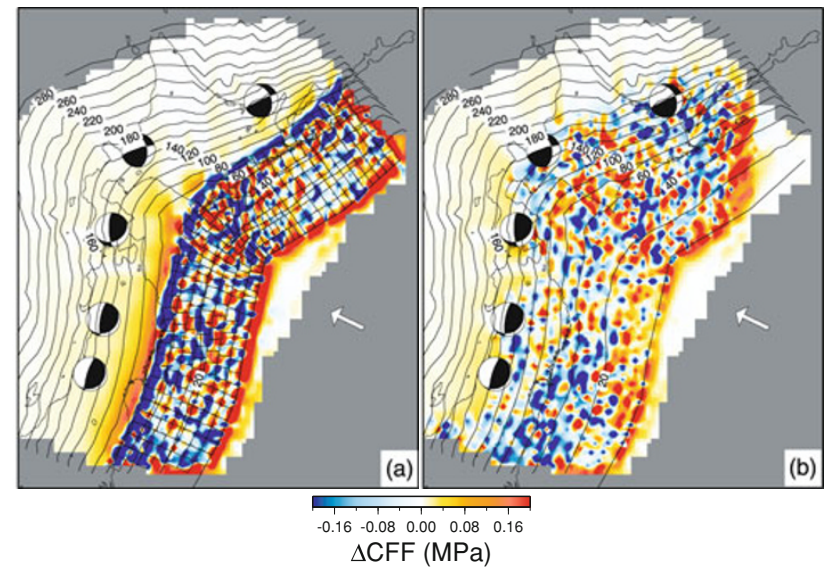

Fig. 8. Plan views of $\triangle \mathrm{CFF}$ for down-dip compression (DC) target fault at $2 \mathrm{~km}$ below the upper plate interface. (a) Uniform model and (b) inhomogeneous model. The mechanism diagrams of the target faults at several selected locations are shown. See the text for details of the target fault parameters. The arrow shows the direction of plate convergence. An aggregate of rectangular faults indicate the locked zone in the uniform model.

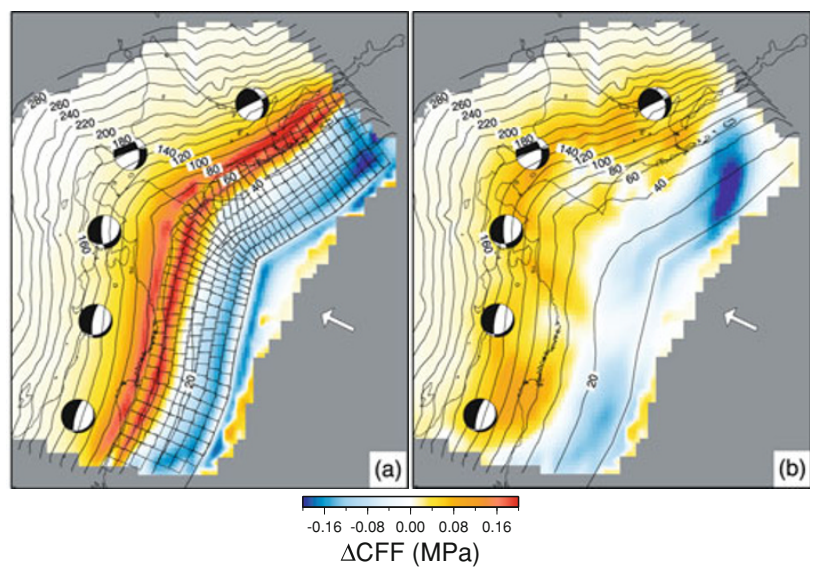

Fig. 9. Plan views of $\triangle \mathrm{CFF}$ for down-dip extension (DE) target fault at $30 \mathrm{~km}$ below the upper plate interface. (a) Uniform model and (b) inhomogeneous model. The mechanism diagrams of the target faults at several selected locations are shown. See the text for details of the target fault parameters. The arrow shows the direction of plate convergence. An aggregate of rectangular faults indicate the locked zone in the uniform model.

end of the locked zone corresponds to the state of stress that was regarded by Douglass and Beffett (1995) as indicating the defect of the back-slip model. Although the inhomogeneous model reduces the amplitude of the negative $\triangle \mathrm{CFF}$, it cannot turn the $\triangle \mathrm{CFF}$ into a positive value. If we look at the $\triangle \mathrm{CFF}$ evaluated at places much closer to the plate interface, the presence of negative $\triangle \mathrm{CFF}$ existing at the down-dip end of the locked zone is more evident.

With respect to the DC-type target fault on the upper seismic plane of the double-planed deep seismic zone (Fig. 8), we find a scattered distribution of positive and negative blobs that are caused by the gaps and overlaps of rectangular faults. If we neglect these singularities, $\triangle \mathrm{CFF}$ on the locked zone is, on average, neutral. In the uniform model, a strong negative zone appears at the down-dip end of the locked zone. This cannot be seen in the inhomogeneous 

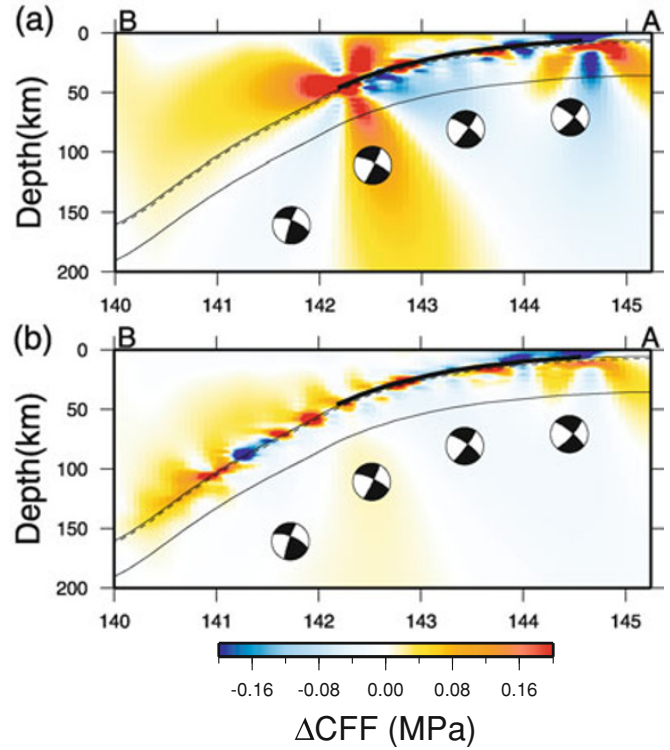

Fig. 10. Cross-sectional views of $\triangle \mathrm{CFF}$ for down-dip compression (DC) target fault along the profile indicated in Fig. 4. (a) Uniform model and (b) inhomogeneous model. The mechanism diagrams of the target faults at several selected locations are shown. These are projected on the backward hemisphere. The two solid lines show the upper plate interface and the place $30 \mathrm{~km}$ below the upper plate interface, respectively. The dashed line indicates the place $2 \mathrm{~km}$ below the upper plate interface. See the text for details of the target fault parameters. The thick line indicates that part of the locked zone in the uniform model.
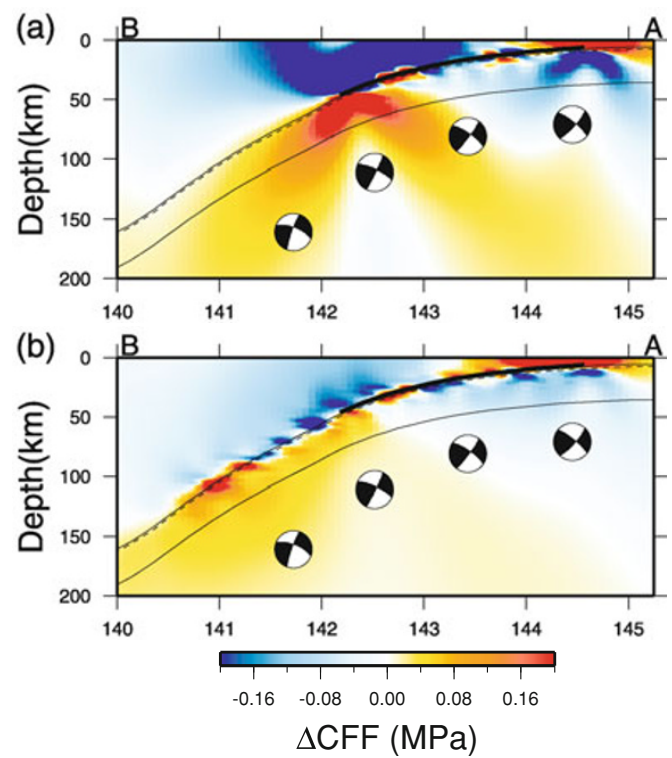

Fig. 11. Cross-sectional views of $\triangle \mathrm{CFF}$ for down-dip extension (DE) target fault along the profile indicated in Fig. 4. (a) Uniform model and (b) inhomogeneous model. The mechanism diagrams of the target faults at several selected locations are shown. These are projected on the backward hemisphere. The two solid lines show the upper plate interface and the place $30 \mathrm{~km}$ below the upper plate interface, respectively. The dashed line indicates the place $2 \mathrm{~km}$ below the upper plate interface. See the text for details of the target fault parameters. The thick line indicates the part of the locked zone in the uniform model.

model. South of the junction, a weak positive zone appears below the down-dip end of the locked zone in both models. A similar positive zone cannot be seen to the north of the junction.

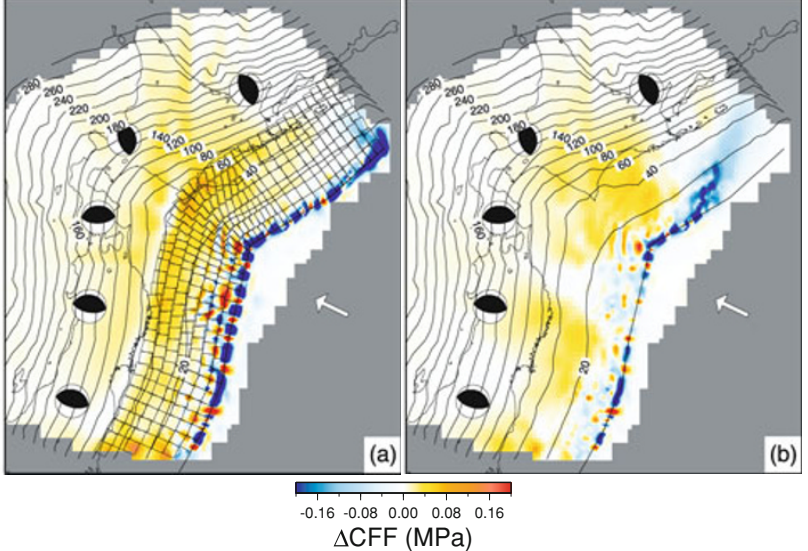

Fig. 12. Plan views of $\triangle \mathrm{CFF}$ for reverse fault with strike normal to the trench. (a) Uniform model and (b) inhomogeneous model. The mechanism diagrams of the target faults at several selected locations are shown. See the text for details of the target fault parameters. The arrow shows the direction of plate convergence. An aggregate of rectangular faults indicate the locked zone in the uniform model.

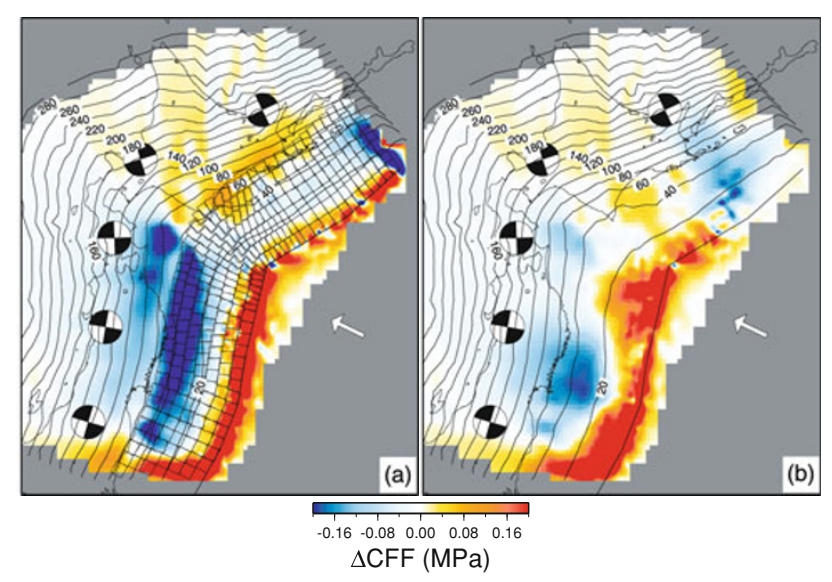

Fig. 13. Plan views of $\triangle \mathrm{CFF}$ for right-lateral strike-slip fault with strike parallel to the trench. (a) Uniform model and (b) inhomogeneous model. The mechanism diagrams of the target faults at several selected locations are shown. See the text for details of the target fault parameters. The arrow shows the direction of plate convergence. An aggregate of rectangular faults indicate the locked zone in the uniform model.

With respect to the DE-type target fault on the lower seismic plane of the double-planed deep seismic zone (Fig. 9), we find a negative zone over the shallower part of the locked zone and a positive zone below the down-dip end of the locked zone.

Figures 10 and 11 show the cross-sectional views of $\triangle \mathrm{CFF}$ for the DC and DE-type target faults along the profile indicated in Fig. 4. The fault parameters of the target faults were given in the same way as described earlier. As a result, given an epicenter, they are uniform at all focal depths. The amplitudes of $\triangle \mathrm{CFF}$ for the DC-type and DE-type target faults are roughly opposite to each other. In the uniform back-slip model, a lobed stress pattern is exhibited at the down-dip end of the locked zone. Although positive zones exist for both target faults, their geometries do not compare well with the geometry of the double-planed deep seismic zone. The diffuse distribution of positive zones cannot explain why the two different types of earthquakes should 
each occur in respective narrow seismic zones.

Although the results are not shown here, we calculated $\triangle \mathrm{CFF}$ for the auxiliary faults of the target faults described above. For the DC and DE-type events, this means that subhorizontal planes were chosen as the target faults instead of the sub-vertical faults. The $\triangle \mathrm{CFF}$ for the two auxiliary faults is known not to be the same unless the internal friction coefficient is zero (Angelier, 2002). However, we found that the difference was small and the main features described above for the sub-vertical faults remain unchanged for the sub-horizontal faults.

In addition to the four target faults that represent the main focal mechanisms in this region, we selected another two target faults in connection with the anomalous state of stress at the junction between the Kuril and northeastern Japan arcs. In order to determine if the focal mechanism with a $P$ axis parallel to the trench can be explained by the back-slip model, we calculated $\triangle \mathrm{CFF}$ for a reverse fault at a depth of $5 \mathrm{~km}$ with its strike perpendicular to the local strike of plate interface beneath each target fault (Fig. 12). The dip was assumed to be 30 degrees northward. The result shows positive amplitudes in the vicinity of the junction. However, the overall pattern of $\triangle \mathrm{CFF}$ does not explain the observation that the earthquakes with the anomalous focal mechanism is restricted in the vicinity of the Hidaka belt (Fig. 1). We also calculated $\triangle \mathrm{CFF}$ for a right-lateral strike-slip fault at a depth of $5 \mathrm{~km}$ with its strike parallel to the local strike of the plate interface beneath its epicenter (Fig. 13). The dip was assumed to be vertical. We chose this target event to see if the oblique subduction enhances the stress field in favor of the transcurrent movement of the forearc sliver on the vertical fault on the continental side (Kimura, 1986; DeMets, 1992). In the uniform model, north of the junction, $\triangle \mathrm{CFF}$ is strongly positive above the down-dip end of the locked zone. This result suggests that under favorable conditions the right-lateral vertical fault tends to be created above the down-dip end of the locked zone. South of the junction, however, $\triangle \mathrm{CFF}$ is negative above the down-dip end of the locked zone. This result arises from the difference in the sense of obliquity between the Kuril and northeastern Japan arc. Along the Kuril arc, the horizontal component of the back slip is left lateral, while it is almost neutral or slightly right lateral along the northeast Japan arc. In the inhomogeneous model, we cannot find such a clear positive zone of $\triangle \mathrm{CFF}$ above the down-dip end of the locked zone as was found in the uniform model. This comparison reveals that the stress in favor of the right-lateral strike-slip fault is created by a strong decrease rate of back slip near the down-dip end of the locked zone.

Using a left-lateral target fault, we tested our uniform model to see if a similar positive $\triangle \mathrm{CFF}$ appears south of the junction. However, $\triangle \mathrm{CFF}$ was nearly neutral above the down-dip end of the locked zone. Whether or not the strong shear stress is created above the lower end of locked zone depends not only on the decrease rate of the back slip at the end of the locked zone but also on the severity of obliquity.

\section{Discussion and Conclusions}

Despite a prominent difference in $\triangle \mathrm{CFF}$ between the two back-slip models at the down-dip end of the locked zone, the wide distribution of positive $\triangle \mathrm{CFF}$ shown in Fig. 6 is consistent with the dominance of focal mechanisms with $P$-axes parallel to the plate motion in the overriding plate. Its amplitude in the land area decreases towards the west from about $0.1 \mathrm{MPa}$ to $0.05 \mathrm{MPa}$ over a distance of about $200 \mathrm{~km}$. For a rigidity of $50 \mathrm{GPa}$, these stresses correspond to a strain rate of $1-2 \times 10^{-7}$ strain/yr, which compares well with the instantaneous strain rate of the Japanese islands estimated using GPS data (Sagiya et al., 2000). If the stress accumulated during the inter-seismic period is released only by earthquakes on the megathrust plate boundary that occur cyclically, say, at a recurrence interval of 100 years, $\triangle \mathrm{CFF}$ can reach an amplitude of about $0.5-1 \mathrm{MPa}$ in the land area. This amplitude of stress is about one order of magnitude smaller than the observed stress drops associated with the intraplate earthquakes in Japan (Kanamori and Anderson, 1975; Utsu, 2001). In northern Honshu, strain accumulation rate during the last 100 years is estimated to be about $5 \times 10^{-8}$, which is three to fivefold larger than the inelastic strain rate estimated from seismic and geological data (Shen-Tu et al., 1995). In order to explain the discrepancy between the short-term and long-term strain rates, Ikeda (1996) inferred that most of the strain accumulated in the last 100 years would be released by a future earthquake on the megathrust plate boundary. If the recurrence interval of the earthquake that resets the accumulated elastic strain in the overriding plate is much longer than 100 years, the stress can increase up to a level comparable to the observed stress drops of intraplate earthquakes. Many large earthquakes along the coast of the Japan Sea in the Tohoku area can be found in historical records (Wesnousky et al., 1982). The high seismicity along the coast of the Japan Sea cannot directly be explained by the distribution of $\triangle \mathrm{CFF}$ in Fig. 6, although this may partly be ascribed to differences in the strength of the crust between the backarc and forearc sides (Sato, 1994). However, we may need to consider the effect of plate coupling along the eastern margin of the Japan Sea (Nakamura, 1983; Hashimoto and Jackson, 1993; Nishimura et al., 2004), which is beyond the scope of this study.

The intrinsic defect of the back-slip model pointed out by Douglass and Buffett (1995) was confirmed for both back-slip models. Within the framework of elasticity, this problem may be solved by a kinematic model similar to that proposed by Zhao and Takemoto (2000).

As described in the previous section, we find it difficult to explain the focal mechanisms of earthquakes in the doubleplaned deep seismic zone by the back-slip model. The stress state within the subducted slab may be determined by the interaction of the slab as a whole with a surrounding viscous mantle (Engdahl and Scholtz, 1977; Sleep, 1979). However, the distributions of $\triangle \mathrm{CFF}$ for the DC-type and DE-type target fault presented in Figs. 8-11 may be useful for predicting the temporal change in the seismicity in the double-planed seismic zone during the interseismic period of large earthquakes on the megathrust plate boundary.

Contrary to our expectation, the present back-slip model cannot provide a sufficient explanation for the stress anomaly at the junction. Other tectonic processes may be involved in generating the anomaly, with the most likely 
candidate being the transcurrent movement of the forearc sliver along the Kuril trench (Kimura, 1986; DeMets, 1992). The collision at the leading margin of the westward moving forearc sliver may be most efficient force producing the strong compression parallel to the trench. The uniform back-slip model can produce the stress field promoting the transcurrent movement above the down-dip end of the locked zone (Fig. 13). However, the inhomogeneous back-slip model does not yield such a strong positive zone of $\triangle \mathrm{CFF}$ for the right-lateral strike-slip fault on the continental side. This suggests that the distribution pattern of back slip at present is not in favor of the transcurrent movement of the forearc sliver along the Kuril arc. Since the transcurrent movement of the forearc sliver is inferred to have occurred in the geologic past (Kimura, 1986), the distribution pattern of the back slip may have been more like the uniform model at that time. In any case, the distribution pattern of back slip near the down-dip end of the locked zone would appear to be an important factor to bear in mind when discussing the tectonics associated with the oblique plate subduction.

Although the back-slip model appears to be useful for explaining the focal mechanisms of earthquakes in the overriding plate, the state of stress in the overriding plate may require a drastic revision when we consider the effect of the steady state subduction. According to Sato and Matsu'ura (1998), the steady state subduction of the oceanic plate produces an ever-increasing extensional stress in the overriding plate. As a result, an extensional stress parallel to the direction of plate convergence would prevail in the long run because the compressional stress due to the plate coupling is released by the repetitive interplate earthquakes.

In conclusion, we assumed the two back-slip models and investigated these to determine if they were able to explain the earthquake focal mechanisms in the Kuril and northeastern Japan arcs. Despite some differences between the two models, the analyses using $\triangle \mathrm{CFF}$ revealed that the backslip models can generally explain the focal mechanisms in the overriding plate. They can also explain the interplate earthquakes on the megathrust plate boundary, although they yield an unphysical stress state that is just below the down-dip end of the locked zone. However, they cannot explain the earthquake focal mechanisms in the double-planed deep seismic zone. The state of stress within the slab may be controlled by the interaction of slab as a whole with the surrounding mantle. Neither can these models fully explain the focal mechanisms with the $P$-axis sub-parallel to the trench that are observed at the junction of the Kuril and northeastern Japan arcs. We infer that other tectonic processes, such as the transcurrent movement of the forearc sliver along the Kuril trench, may be involved in producing the anomaly. The present results suggest that the distribution pattern of back slip at the down-dip end of the locked zone is important in any discussion of the tectonics associated with the oblique plate subduction.

Acknowledgments. We thank $M$. Kosuga for reading the manuscript and giving valuable comments. We are also grateful to anonymous reviewers for comments that greatly assisted in the revision of the manuscript. The hypocenter parameters used in this study are taken from the Annual Seismological Bulletin of
Japan (CD ROM) published by the Japan Meteorological Agency (JMA). We thank A. Ono for her help in preparing the figures. The figures are prepared using GMT (Wessel and Smith, 1991).

\section{References}

Anderson, D. L., Theory of the Earth, 366 pp., Cambridge Univ. Press, London, 1989.

Angelier, J., Inversion of earthquake focal mechanism to obtain the seismotectonic stress IV - a new method free of choice among nodal planes, Geophys. J. Int., 150, 588-609, 2002.

DeMets, C., Oblique convergence and deformation along the Kuril and Japan trenches, J. Geophys. Res., 97, 17615-17625, 1992.

DeMets, C., R. G. Gordon, D. F. Argus, and S. Stein, Effect of recent revisions to the geomagnetic reversal time scale on estimates of current plate motions, Geophys. Res. Lett., 21, 2191-2194, 1994.

Douglass, J. J. and B. A. Buffett, The stress state implied by dislocation models of subduction deformation, Geophys. Res. Lett., 22, 3115-3118, 1995.

Douglass, J. J. and B. A. Buffett, Reply, Geophys. Res. Lett., 23, 27112712, 1996.

Engdahl, E. R. and C. H. Scholz, A double Benioff zone beneath the central Aleutioans: An unbending of the lithosphere, Geophys. Res. Lett., 4, 473-476, 1977.

Goto, K., H. Hamaguchi, and Z. Suzuki, Earthquake generating stresses in a descending slab, Tectonophysics, 112, 111-128, 1985.

Hasegawa, A., N. Umino, and A. Takagi, Double-planed structure of the deep seismic zone in the northeastern Japan arc, Tectonophysics, 47, 43-58, 1978.

Hasegawa, A., N. Umino, A. Takagi, S. Suzuki, Y. Motoya, S. Kameya, K. Tanaka, and Y. Sawada, Spatial distribution of earthquakes beneath Hokkaido and northern Honshu, Japan, Zisin 2, 36, 129-150, 1983 (in Japanese with English abstract).

Hashimoto, M., Finite element modeling of deformations of the lithosphere at an arc-arc junction: The Hokkaido corner, Japan, J. Phys. Earth, 32, 373-398, 1984.

Hashimoto, M. and D. D. Jackson, Plate tectonics and crustal deformation around the Japanese islands, J. Geophys. Res., 98, 16149-16166, 1993.

Hirata, N., T. Kanazawa, K. Suyehiro, and H. Shimamura, A seismicity gap beneath the inner wall of the Japan trench as derived by ocean bottom seismograph measurement, Tectonophysics, 112, 193-209, 1985.

IFREE/JAMSTEC, Database of the crustal structure obtained from exploration seismology, http://www.jamstec.go.jp/jamstec-j/IFREE_center, 2007.

Igarashi, T., T. Matsuzawa, N. Umino, and A. Hasegawa, Spatial distribution of focal mechanisms for interplate and intraplate earthquakes associated with the subducting Pacific plate beneath the northeastern Japan arc: A triple-planed deep seismic zone, J. Geophys. Res., 106(B2), 2177-2192, 10.1029/2000JB900386, 2001.

Ikeda, Y., Implications of active fault study for the present-day tectonics of the Japan arc, Active Fault Res., 15, 93-99, 1996 (in Japanese with English abstract).

Ito, T., S. Yoshioka, and S. Miyazaki, Interplate coupling in northeast Japan deduced from inversion analysis of GPS data, Earth Planet. Sci. Lett., 176,117-130, 2000.

Kanai, T., T. Miyamura, Y. Oishi, and A. Makinouchi, CHIKAKU DB/CAD: A System for Modeling 3D Tectonic Structure, ComputerAided Design and Applications, Proc. CAD'05 Conference, Bangkok, Thailand, 20-24 June, 2005, 2, 403-410, 2005.

Kanamori, H. and D. L. Anderson, Theoretical basis of some empirical relations in seismology, Bull. Seismol. Soc. Am., 65, 1073-1095, 1975.

Kato, T., K. Shimazaki, and K. Yamashina, State of stress within a thin elastic wedge: a model of internal deformation of the continental plate at arc-arc junctions, Geophys. J. Astr. Soc., 60, 377-390, 1980.

Katsumata, K., N. Wada, and M. Kasahara, Newly imaged shape of the deep seismic zone within the subducting Pacific plate beneath the Hokkaido corner, Japan-Kuril arc-arc junction, J. Geophys. Res., 108(B12), 2565, doi:10.1029/2002JB002175, 2003.

Kimura, G., Oblique subduction and collision: Forearc tectonics of the Kuril arc, Geology, 14, 404-407, 1986.

Koketsu, K., K. Hikima, S. Miyazaki, and S. Ide, Joint inversion of strong motion and geodetic data for the source process of the 2003 Tokachioki, Hokkaido, earthquake, Earth Planets Space, 56, 329-334, 2004.

Kosuga, M., T. Sato, A. Hasegawa, T. Matsuzawa, S. Suzuki, and Y. Motoya, Spatial distribution of intermediate-depth earthquakes with horizontal or vertical nodal planes beneath northeastern Japan, Phys. Earth 
Planet. Inter., 93, 63-89, 1996.

Matsuzawa, T., T. Kono, A. Hasegawa, and A. Takagi, Subducting plate boundary beneath the northeastern Japan arc estimated from SP converted waves, Tectonophysics, 181, 123-133, 1990.

Mazzotti, S., X. Le Pichon, P. Henry, and S. Miyazaki, Full interseismic locking of the Nankai and Japan-west Kuril subduction zones: an analysis of uniform elastic strain accumulation in Japan constrained by permanent GPS, J. Geophys. Res., 105, 13159-13177, 2000.

Minamino, T. and N. Fujii, The effect of the contorted 'noise' of a subducting slab on the stress field in the continental lithosphere at an arc-arc junction, Geophys. J. Astr. Soc., 67, 145-158, 1981.

Miyamura, J. and T. Sasatani, Accurate determination of source depths and focal mechanisms of shallow earthquakes occurring at the junction between the Kuril and the Japan trenches, J. Fac. Sci., Hokkaido Univ., Ser. VII (Geophysics), 8, 37-63, 1986.

Miyazaki, S., Y. Hatanaka, T. Sagiya, and T. Tada, The nationwide GPS array as an earth observation system, Bull. Geogr. Surv. Inst., 44, 11-22, 1998.

Moriya, T., H. Miyamachi, and S. Kato, Spatial distribution and mechanism solutions for foreshocks, mainshock, and aftershocks of the Urakawa-oki earthquake of March 21, 1982, Geophys. Bull. Hokkaido Univ., 42, 191-214, 1983 (in Japanese with English abstract).

Nakamura, K., Possible nascent trench along the eastern Japan Sea as the convergence boundary between Eurasian and North American plates, Bull. Earthquake Res. Inst. Univ. Tokyo, 58, 711-722, 1983 (in Japanese with English abstract).

Nakane, K., Horizontal tectonic strain in Japan (I) and (II), J. Geodyn. Soc. Jpn., 19, 190-208, 1973 (in Japanese with English abstract).

Nishimura, T., S. Miura, K. Tachibana, K. Hashimoto, T. Sato, S. Hori, E. Murakami, T. Kono, K. Nida, M. Mishina, T. Hirasawa, and S. Miyazaki, Distribution of seismic coupling on the subducting plate boundary in northeastern Japan inferred from GPS observations, Tectonophysics, 323, 217-238, 2000.

Nishimura, T., T. Hirasawa, S. Miyazaki, T. Sagiya, T. Tada, S. Miura, and K. Tanaka, Temporal change in interplate coupling in northeastern Japan during 1995-2002 estimated from continuous GPS observations, Geophys. J. Int., 157, 901-916, 2004.

Okada, Y., Internal deformation due to shear and tensile faults in a halfspace, Bull. Seismol. Soc. Am., 82, 1018-1040, 1992.

Okubo, S., Coseismic crustal movement in a spherically symmetric earth, Proceedings of the CRCM '93, Kobe, 275-278, 1993.

Sagiya, T., S. Miyazaki, and T. Tada, Continuous GPS array and presentday crust deformation of Japan, Pure Appl. Geophys., 157, 2303-2322, 2000 .

Sasatani, T., Mechanism of mantle earthquakes near the junction of the Kuril and the northern Honshu arcs, J. Phys. Earth, 24, 341-354, 1976.

Sato, H., The relationship between late Cenozoic tectonic events and stress field and basin development in Northeast Japan, J. Geophys. Res., 99, 22261-22274, 1994.

Sato, T. and M. Matsu'ura, Modeling stress accumulation and the crustal deformation cycle associated with repetition of large earthquakes at a plate boundary, Zisin 2, suppl., 50, 283-292, 1998 (in Japanese with English abstract).

Sato, T., K. Tanaka, and H. Sato, Recent seismic activity and earthquake generating stress field in the northern part of the Tohoku region, Sci. Rep. Hirosaki Univ., 27, 33-45, 1980 (in Japanese with English abstract).

Savage, J. C., A dislocation model of strain accumulation and release at a subduction zone, J. Geophys. Res., 88, 4984-4996, 1983.

Savage, J. C., Comments on "The stress state implied by dislocation models of subduction deformation" by J. J. Douglass and B. A. Buffett, Geo- phys. Res. Lett., 23, 2709-2710, 1996.

Shen-Tu, B. and W. E. Holt, Interseismic horizontal deformation in northern Honshu and its relationship with the subduction of the Pacific plate in Japan trench, Geophys. Res. Lett., 23, 3103-3106, 1996.

Shen-Tu, B., W. E. Holt, and A. J. Haines, Intraplate deformation in the Japanese Islands: A kinematic study of intraplate deformation at a convergent plate margin, J. Geophys. Res., 100, 24275-24293, 1995.

Shimazaki, K., T. Kato, and K. Yamashina, Basic type of internal deformation of continental plate at arc-arc junctions, J. Phys. Earth, 26, S69S83, 1978.

Sleep, N. H., The double seismic zone in downgoing slabs and the viscosity of the mesosphere, J. Geophys. Res., 84, 4565-4571, 1979.

Stauder, W. and L. Mualchin, Fault motion in the larger earthquakes of the Kuril-Kamchatka arc and of the Kuril-Hokkaido corner, J. Geophys. Res., 81, 297-308, 1976.

Suetsugu, D. and I. Nakanishi, Re-examination of fault model for the 1982 Urakawa-Oki earthquake by analyses of seismic, geodetic, and tsunami data, J. Phys. Earth, 36, 53-67, 1988.

Sun, W. and S. Okubo, Surface potential and gravity changes due to internal dislocations in a spherical earth-I. Theory for a point dislocation, Geophys. J. Int., 114, 569-592, 1993.

Suwa, Y., S. Miura, A. Hasegawa, T. Sato, and K. Tachibana, Interplate coupling beneath NE Japan inferred from three-dimensional displacement field, J. Geophys. Res., 111, B04402, doi:10.1029/2004 JB003203, 2006.

Suzuki, S., Y. Motoya, N. Umino, A. Hasegawa, S. Kameya, and K. Tanaka, Hypocentral distribution and composite focal mechanisms of shallow earthquakes near the junction between the Kuril and the northeastern Japan arcs, Zisin 2, 36, 407-421, 1983a (in Japanese with English abstract).

Suzuki, S., T. Sasatani, and Y. Motoya, Double seismic zone beneath the middle of Hokkaido, Japan, in the southwestern side of the Kurile arc, Tectonophysics, 96, 59-76, 1983 b.

Umino, N. and A. Hasegawa, A detailed structure of the deep seismic zone and earthquake mechanism in the northeastern Japan arc, Zisin 2, 35, 237-257, 1982 (in Japanese with English abstract).

Umino, N., A. Hasegawa, A. Takagi, S. Suziki, Y. Motoya, A. Kameya, K. Tanaka, and Y. Sawada, Focal mechanisms of intermediate-depth earthquakes beneath Hokkaido and northern Honshu, Japan, Zisin 2, 37, 523-538, 1984 (in Japanese with English abstract).

Utsu, T., Seismology (Third edition), 376 pp., Kyoritsu Pub. Co., Tokyo, 2001.

Wesnousky, S. G., C. H. Scholz, and K. Shimazaki, Deformation of an island arc; rates and moment release and crustal shortening in intraplate Japan determined from seismicity and Quaternary fault data, J. Geophys. Res., 87, 6829-6852, 1982.

Wessel, P. and W. H. F. Smith, Free software helps map and display data, EOS Trans. AGU, 72, 441, 1991.

Yoshii, T., A detailed cross-section of the deep seismic zone beneath northeastern Honshu, Japan, Tectonophysics, 55, 349-360, 1979.

Zhao, D., T. Matsuzawa, and A. Hasegawa, Morphology of the subducting slab boundary in the northeastern Japan arc, Phys. Earth Planet. Inter., 102, 89-104, 1997.

Zhao, S. and S. Takemoto, Deformation and stress change associated with plate interaction at subduction zones: a kinematic modeling, Geophys. J. Int., 142, 300-318, 2000.

M. Takeuchi, T. Sato (e-mail: tamao@cc.hirosaki-u.ac.jp), and T. Shinbo 